\title{
PENINGKATAN KEMAMPUAN PENGELOLAAN PENILAIAN KURIKULUM 2013 MELALUI PENDAMPINGAN BAGI GURU SEKOLAH DASAR
}

\section{Nurkhan $\bowtie$}

UPT Pendidikan Kecamatan Jekulo Kudus

Jawa Tengah, Indonesia

\section{Info Artikel}

Sejarah Artikel: Diterima September 2016

Disetujui November 2016 Dipublikasikan Desember 2016

\section{Keywords:}

Assistance, evaluation, Curriculum.

\section{Abstract}

The purpose of this study was to determine the success and effectiveness of the model of assistance in improving the management capacity assessment for elementary school teachers curriculum objectives 2013. These investigators use techniques: lectures, discussions, drafting instruments, assessment practices. This mentoring models, proved successful and effective in improving the ability of the management judging Goal Curriculum for elementary school teachers in 2013, it can be proven by the data analysis showed no improvement, the average rose 28.7 points, or $23.9 \%$.

\section{Abstrak}

Tujuan penelitian ini adalah untuk mengetahui keberhasilan dan efektifitas model pendampingan dalam meningkatkan kemampuan pengelolaan penilaian bagi guru SD sasaran Kurikulum 2013. Dalam penelitian ini peneliti menggunakan teknik : ceramah, diskusi, penyusunan instrumen, praktik penilaian. Model pendampingan ini, terbukti berhasil dan effektif dalam meningkatkan kemampuan pengelolaan penilian bagi guru SD Sasaran Kurikulum 2013, hal ini bisa dibuktikan dengan analisis data yang menunjukkan ada peningkatkan, yaitu rata-rata naik 28,7 poin atau $23,9 \%$

(C) 2016 Universitas Muria Kudus

\begin{tabular}{lr}
\hline Alamat korespondensi: & p-ISSN 2087-9385 \\
Program Studi Pendidikan Guru Sekolah Dasar & e-ISSN 2528-696X \\
Fakultas Keguruan dan Ilmu Pendidikan Universitas Muria Kudus & \\
Kampus UMK Gondangmanis, Bae Kudus Gd. L. 1t I PO. BOX 53 & \\
Kudus & \\
Tlp (0291)438229 ex.147 Fax. (0291) 437198 & \\
E-mail: nur.khan85@yahoo.co.id &
\end{tabular}




\section{PENDAHULUAN}

Permasalahan yang muncul dalam implementasi Kurikulum 2013 diantaranya : 1) guru-guru SD sasaran Kurtilas yang mengajar di kelas rendah ( kelas I, IV ) belum sepenuh nya mampu menerapkan pembelajaran tematik integratif seperti yang diisyarat- kan oleh kurikulum 2013, walaupun mereka sudah pernah mendapat sosialisasi pembelajaran tematik, 2) Guru-guru SD sasaran Kurikulum 2013 terutama yang mengajar di kelas tinggi (kelas, V, dan VI) belum memahami dan belum pernah menerapkan pembela jaran tematik. 3) Kurangnya pendampi -ngan bagi guru-guru SD dalam pelak- sanaan kurikulum 2013, walaupun sosialisasi dan workshop mengenai kurikulum 2013 sudah pernah mereka ikuti. 4) Guru-guru SD sasaran imple- mentasi Kurikulum 2013 merasa kesulitan dalam pengelolaan penilaian karena jumlah dan bentuk penilaian sangat rumit dan jumlah soalnya banyak sekali.

Kondisi yang ada, pengawas sekolah masih belum maksimal men- dampingi guruguru dalam pelaksanaan pembelajaran tematik terpadu khusus- nya yang terkait dengan penilaian. hal tersebut dikarenakan pengetahuan dan kemampuan pengawas sekolah tentang pembelajaran tematik terpadu khusus- nya masalah penilaiannya masih sebatas hasil pelatihan sehingga belum maksimal mendam pingi guru-guru di sekolah sasaran Kurikulum 2013, sedangkan guru itu sendiri lamban sekali dalam memahami kosep dan model pembelajaran Kurikulum 2013, sehingga dampaknya guru merasa kesulitan dalam melaksanakan kurikulum 2013 khususnya masalah yang terkait dengan pengelolaan penilaian.

Berdasarkan uraian di atas dan hasil supervisi, wawancara serta peng- amatan langsung di sekolah sasaran kurikulum 2013 ditemukan enam ma salah pokok yang menyebabkan ter hambatnya implementasi kurikulum 2013 di sekolah yakni: (1) guru ku rang menguasai pendekatan saintifik, beserta model-model pembelajarannya, (2) guru kurang memahami konsep penilaian yang amat rumit dan komplek. (4) guru kurang menguasai penggunaan komputer (5) guru mendsetnya redah sehingga sulit untuk diajak melakukan pembaharuan, dan merosotnya komit- men guru dalam menjalankan tugasnya, (6) terbatasnya kemampuan pengawas dalam pengelolaan penilaian.

Memperhatikan data dan fakta di atas yang telah penulis paparkan, maka ke enam masalah tersebut khususnya masalah pengelolaan penilaian, guru perlu segera mendapat pendampingan pengelolaan penilaian sampai tuntas, sehingga guru tidak lagi merasa sulit dalam hal pengelolaan penilaian. Salah satu model yang tepat untuk menyelesiakan masalah di atas adalah dengan menerapkan model pendam- pingan. Dengan alasan bahwa model ini lebih luwes, memberikan bantuan sesuai kesulitan yang dialami guru dengan model yang tepat, dan akan mendampingi guru hingga permasalah nnya tuntas. Atas pemahaman tersebut maka peneliti tertarik untuk melakukan penelitian tindakan dengan tema peningkatan kemampuan guru dalam pengelolaan penilaian kurtilas melalui model pendampinngan.

Berdasarkan latar belakang masalah di atas, maka dalam penelitian ini dapat diidentifikasi beberapa permasalahan yakni:1 ) Isi kuikulum 2013 yang menyangkut konsep, pendekatan, model pembela jaran, dan pengelolaan penilaian belum sepenuhnya di kuasai oleh guru sehingga guru merasa sulit dalam pembelajaran Kuurikulum 2013, salah satu masalah yang paling krusial adalah pengelolaan penilaian. 2) Rendahnya mendset guru dalam melakukan pembaharuan kurikulum, walaupun mereka sudah mengikuti diklat maupun pendampingan dari pengawas.

Berdasarkan identifikasi masalah di atas, dan banyaknya masalah dalam implementasi kurikulum 2013. maka dalam penelitian ini peneliti lebih fokus pada upaya meningkatkan kemampuan guru dalam pengelolaan penilaian. Hal ini dimaksudkan agar permasalahan yang akan diteliti dengan model pendam- pingan, lebih terfokus pada pokok permasalahannya,sehingga pembahasan- nya akan lebih sistematis, mendalam,dan menghasilkan produk yang benar-benar berkualitas. maka rumusan masalah yang akan diungkap dalam penelitian ini adalah: 1) Apakah model pendampingan dapat meningkatkan kemampuan pengelolaan penilaian, bagi guru SD sasaran implementasi Kurikulum 2013, 2) Bagai- mana efektifitas model pendampingan dalam meningkatkan kemampuan pengelolaan penilaian bagi guru SD Sasaran implementasi Kurikulum 2013 di UPT Pendidikan Kecamatan Jekulo?

Berdasarkan rumusan masalah di atas, maka tujuan yang ingin dicapai, dalam Penelitian ini : 1) Untuk menge -tahui keberhasilan model pendampi- ngan dalam meningkatkan kemampuan pengelolaan penilaian bagi guru SD sasaran implementasi Kurikulum 2013. 2) Untuk mengetahui efektifitas model pendampingan dalam peningka- tan kemampuan pengelolaan penilaian bagi guru SD sasaran implementasi 
Kurikulum 2013 di UPT Pendidikan Kecamatan Jekulo.

Permendikbud No 53 Tahun 2015 menyebutkan bahwa lingkup Penilaian pendidikan pada pendidikan dasar dan pendidikan menengah terdiri atas: 1) a).Penilaian hasil belajar oleh pendidik, b) penilaian hasil belajar oleh satuan pendidikan, c) dan penilaian hasil belajar oleh Pemerintah. 2) Penilaian hasil belajar peserta didik pada pendidikan dasar dan pendidikan menengah meliputi tiga aspek: a) Sikap, b) Pengetahuan, dan c) keterampilan. 3) Penilaian sikap merupakan kegiatan yang dilakukan oleh pendidik untuk memperoleh informasi deskriptif mengenai perilaku peserta didik. 4) Penilaian pengetahuan merupakan kegiatan yang dilakukan untuk mengukur penguasaan pengetahuan peserta didik. 5) Penilaian keterampilan merupakan kegiatan yang dilakukan untuk mengukur kemampuan peserta didik menerapkan pengetahuan dalam melakukan tugas tertentu. 6) Penilaian pengetahuan dan keterampilan dilaku- kan oleh pendidik, satuan pendidikan, dan/atau Pemerintah. Tujuan Penilaian :1) penilaian hasil belajar oleh pendidik bertujuan untuk memantau dan mengevaluasi proses, kemajuan belajar, dan perbaikan hasil belajar peserta didik secara berkesinam- bungan. 2) penilaian hasil belajar oleh satuan pendidikan bertujuan untuk menilai pencapaian Standar Kompetensi Lulusan untuk semua mata pelajaran. 3) penilaian hasil belajar oleh Pemerintah bertujuan untuk menilai pencapaian kompetensi lulusan secara nasional pada mata pelajaran tertentu.

Prinsip Penilaian Hasil Belajar: 1) sahih, berarti penilaian didasarkan pada data yang mencerminkan kemampuan yang diukur,2) objektif, berarti penilai- an didasarkan pada prosedur dan kriteria yang jelas, tidak dipengaruhi subjektivitas penilai. 3) adil, berarti penilaian tidak menguntungkan atau merugikan peserta didik karena berkebutuhan khusus serta perbedaan latar belakang agama, suku, budaya, adat istiadat, status sosial ekonomi, dan gender. 4) Terpadu, berarti penilaian merupakan salah satu komponen yang tak terpisahkan dari kegiatan pembelajaran. 5) Terbuka, berarti prose- dur penilaian, kriteria penilaian, dan dasar pengambilan keputusan dapat diketahui oleh pihak yang berkepenti- ngan. 6) menyeluruh dan berkesinam- bungan, berarti penilaian mencakup semua aspek kompetensi dengan menggunakan berbagai teknik penilaian yang sesuai, untuk memantau dan menilai perkembangan kemampuan peserta didik, 7) sistematis, berarti penilaian dilakukan secara berencana dan bertahap dengan mengikuti langkah-langkah baku, 8) Beracuan kriteria, berarti penilaian didasarkan pada ukuran pencapaian kompetensi yang ditetapkan.9) akuntabel, berarti penilaian dapat dipertanggungjawabkan, baik dari segi mekanisme, prosedur, teknik, maupun hasilnya. berarti penilaian didasarkan pada ukuran pencapaian kompetensi yang ditetapkan.9) akuntabel, berarti penilai- an dapat dipertanggungjawab kan, baik dari segi mekanisme, prosedur, teknik, maupun hasilnya.

Bentuk penilaian : 1) penilaian hasil belajar oleh pendidik dilakukan dalam bentuk ulangan, pengamatan, penugasan, dan/atau bentuk lain yang diperlukan.2 ) penilaian hasil belajar oleh pendidik digunakan untuk: a) mengukur dan mengetahui pencapaian kompetensi peserta didik b) memper- baiki proses pembelajaran; c) menyu- sun laporan kemajuan hasil belajar harian, tengah semester, akhir semester, akhir tahun. dan/atau kenai - kan kelas. 3) Penilaian hasil belajar oleh satuan pendidikan dilakukan dalam bentuk ujian sekolah/madrasah. 4) Penilaian hasil belajar oleh satuan pendidikan digunakan untuk penentuan kelulusan dari satuan pendidikan. Satuan pendidikan menggunakan hasil penilaian oleh pendidik untuk melaku- kan perbaikan dan/atau penjaminan mutu pendidikan. 5) Penilaian hasil belajar oleh Pemerintah dilakukan dalam bentuk Ujian Nasional dan/atau bentuk lain yang diperlukan. Mekanisme penilaian hasil belajar oleh pendidik: 1) perancangan strategi penilaian oleh pendidik dilakukan pada saat penyusunan rencana pelaksanaan pembelajaran (RPP) berdasarkan silabus, 2) penilaian aspek sikap dilakukan melalui observasi/pengama- tan dan teknik penilaian lain yang relevan, dan pelaporannya menjadi tanggungjawab wali kelas atau guru kelas. 3) penilaian aspek pengetahuan dilakukan melalui tes tertulis, tes lesan dan penugasan sesuai dengan kompetensi yang dinilai. 4) penilaian keterampilan dilakukan melalui praktik, produk, proyek, portofolio, dan/atau teknik lain sesuai dengan kompetensi yang dinilai, 5) peserta didik yang belum mencapai KKM satuan pendidikan harus mengikuti pembelajaran remedi. 6) hasil penilaian pencapaian pengetahuan dan keterampilan peserta didik disampaikan dalam bentuk angka dan/atau deskripsi.

Pengertian Pendampingan:Kemendikbud (2016) menyebutkan bahwa pendampingan implementasi Kuriku lum adalah proses pemberian bantuan penguatan 
pelaksanaan Kurikulum yang diberikan oleh pengawas kepada kepala sekolah dan guru yang telah dilatih Kurikulum 2013. Pendampingan ini dapat diberikan kepada tenaga kependidikan lainnya, orangtua murid / komite sekolah, dan pemangku kepentingan sekolah.

Menurut Kamil (2010: 169) pendampingan adalah suatu kegiatan yang dilakukan seseorang yang bersifat konsultatif, interaktif, komunikatif, motivatif, dan negosiatif. Konsultatif yang dimaksud adalah pendamping mampu menciptakan suatu kondisi dimana pendamping maupun yang didampingi bisa berkonsultasi dalam memecahkan masalah bersama-sama, interaktif artinya antara pendamping dan yang didampingi harus samasama aktif, komunikatif maksudnya adalah apa yang disampaikan pendamping atau yang didampingi dapat dipahami bersama (persamaan pemahaman), motivatif maksudnya pendamping harus dapat menumbuhkan keperca- yaan diri dan dapat memberikan semangat/motivasi, dan negosiasi maksudnya pendamping dan yang didampingi mudah melakukan kesepakatan bersama. semangat/motivasi, dan negosiasi maksudnya pendamping dan yang didampingi mudah melakukan kesepakatan bersama.

Berdasarkan uraian di atas dapat ditarik kesimpulan bahwa yang dimaksud dengan pendampingan ialah memberikan penguatan atau bantuan untuk meningkatkan kemampuan proesional oleh pengawas atau instruktur kepada guru yang sudah mendapat pelatihan kurikulum, melalui prosedur yang telah ditentukan, hingga guru tersebut benar benar menguasai materi yang disampaikan pengawas atau instruktur.

Tujuan Pendampingan dalam penelitian ini adalah : 1) meningkatkan kemampuan guru dalam pembela jaran Kurikulum 2013, khususnya yang menyangkut masalah pengelola- an penilaian 2) menambah khasanah keilmuan bagi guru sasaran Kurikulum 2013, 3) membantu guru mengatasi kesulitan dalam pengelolaan penilaian. 4) membangun budaya mutu di sekolah dasar, 5) membantu guru dalam pemanfaatan teknologi informasi dalam pengelolaan penilaian, 6) melatih guru agar lebih kreatif, inovati, tidak merasa terbebani dalam pengelolaan penilaian.

\section{METODE PENELITIAN}

Hal penting dalam PTS adalah tindakan nyata (action) yang dilakukan oleh kepala sekolah/pengawas, untuk memecahkan masalah yang dihadapi dalam proses belajar menga- jar. Tindakan itu harus diren- canakan dengan baik dan dapat diukur tingkat keberhasilannya.Jika ternyata program tersebut belum dapat memecahkan masalah yang ada, maka perlu dilaku- kan penelitian siklus berikutnya (siklus kedua) untuk mencoba tindakan lain (alternatif pemecahan lain sampai permasalahan selesai)

Sumber data penelitian meliputi tempat dan kegiatan penelitian, yakni berbagai kegiatan pendampingan yang berlangsung di SD sasaran Kurikulum 2013 di UPT Pendidikan Kecamatan Jekulo semester 1 tahun pelajaran 2016 / 2017, yang dialami bersama oleh guru dan peneliti baik sebelum tindakan (surveyawal) maupun setelah dilaksana- kan. Informan dalam penelitian ini adalah seluruh kepala sekolah / guru SD sasaran Kurtilas di UPT Pendidikan Kecamatan Jekulo.

Sumber data primer diperoleh dari hasil wawancara, observasi, pencerma- tan data dengan guru SD sasaran Kurtilas di UPT Pendidikan Kecamatan Jekulo. Sedangkan sumber data sekunder diambil berdasarkan hasil kajian dokumentasi dan pengamatan personal, data primer bisa diambil di perpustakaan atau administrasi guru.

Teknik dan alat pengumpulan data instrumen penelitian adalah alat atau fasilitas yang digunakan oleh peneliti dalam mengumpulkan data agar pekerjaannya lebih mudah dan hasilnya lebih baik, dalam arti lebih cermat, lengkap, serta sistematis sehingga lebih mudah diolah (Arikunto, 2006:136). Instrumen dalam penelitian ini diguna- kan untuk mengungkap data kualitatif dan data kuantitatif.

Kajian Dokumen Arikunto (2002: 134) menjelaskan teknik dokumentasi adalah mencari data mengenai hal-hal atau variabel yang berupa catatan, transkip nilai, buku, agenda untuk memperoleh keterangan yang berwujud data yang berkaitan dengan objek yang diteliti memperoleh keterangan yang berwu -jud data yang berkaitan dengan objek yang diteliti.

Sugiyono (2010 : 194) menjelas- kan wawancara digunakan sebagai teknik pengumpulan data apabila peneliti ingin melakukan studi pendahuluan untuk menemukan permasalahan yang harus diteliti, dan juga apabila peneliti ingin mengetahui halhal dari responden yang lebih mendalam.

Untuk memperoleh data yang valid, perlu dilakukan teknik-teknik uji validitas yaitu triangulasi sumber data dan triangulasi metode. Dalam penelitian ini, peneliti mengumpulkan data dari berbagai sumber yang berbeda. Data yang bersumber dari guru dicek kebenarannya dengan dokumen-dokumen pendukung serta pernyataan-pernyataan informan. Data yang terkumpul diuji validitasnya dengan beberapa metode. Data yang terkumpul dari kegiatan observasi dicek kebenarannya melalui kegiatan 
wawancara untuk mengungkap kemampuan guru dalam pengelolaan penilaian.

Teknik analisis data yang digunakan dalam penelitian ini adalah teknik analisis kritis. Teknik analisis ini bertujuan untuk mengungkap kekurangan dan kelebihan kemampuan guru, selama penelitian berlangsung. Kriteria dalam teknik ini berdasar pada kajian teoretis yang telah dipaparkan sebelumnya. Hasil analisis itu dijadikan acuan untuk menyusun rencana tindakan kelas berikutnya sesuai dengan siklus yang telah ditetapkan antara guru, peneliti dan ke-pala sekolah SD Inti.

Analisis kritis terhadap kemampuan guru dalam pengelolaan penilaian meliputi : (1) pemahaman konsep kurikulum2013 (2) pemahaman konsep penilaian kurikulum 2013(3) penyusunan instrumen penilaian (4) perencanaan penilaian (5) pelaksanaan penilaian (6) mengolah nilai.

Prosedur penelitian merupakan sebuah rangkaian tahap penelitian dari awal sampai akhir. Penelitian ini merupakan proses pengkajian sistem berdaur sebagaimana kerangka berpikir yang dikembangkan oleh Suhardjono (dalam Arikunto dkk, 2006:74). Prosedur penelitian ini mencakup tahap-tahap: (1) persiapan, (2) studi/survei awal, (3) pelaksanaan siklus, dan (4) penyusunan laporan. Pelaksanaan siklus terdiri-dari: (a) perencanaan tindakan (planning), (b) pelaksanaan tindakan (acting), (c) pengamatan (observing), (d) refleksi (reflecting). PTS merupakan penelitian yang bersiklus. Alur PTS dapat dilihat pada Gambar berikut:

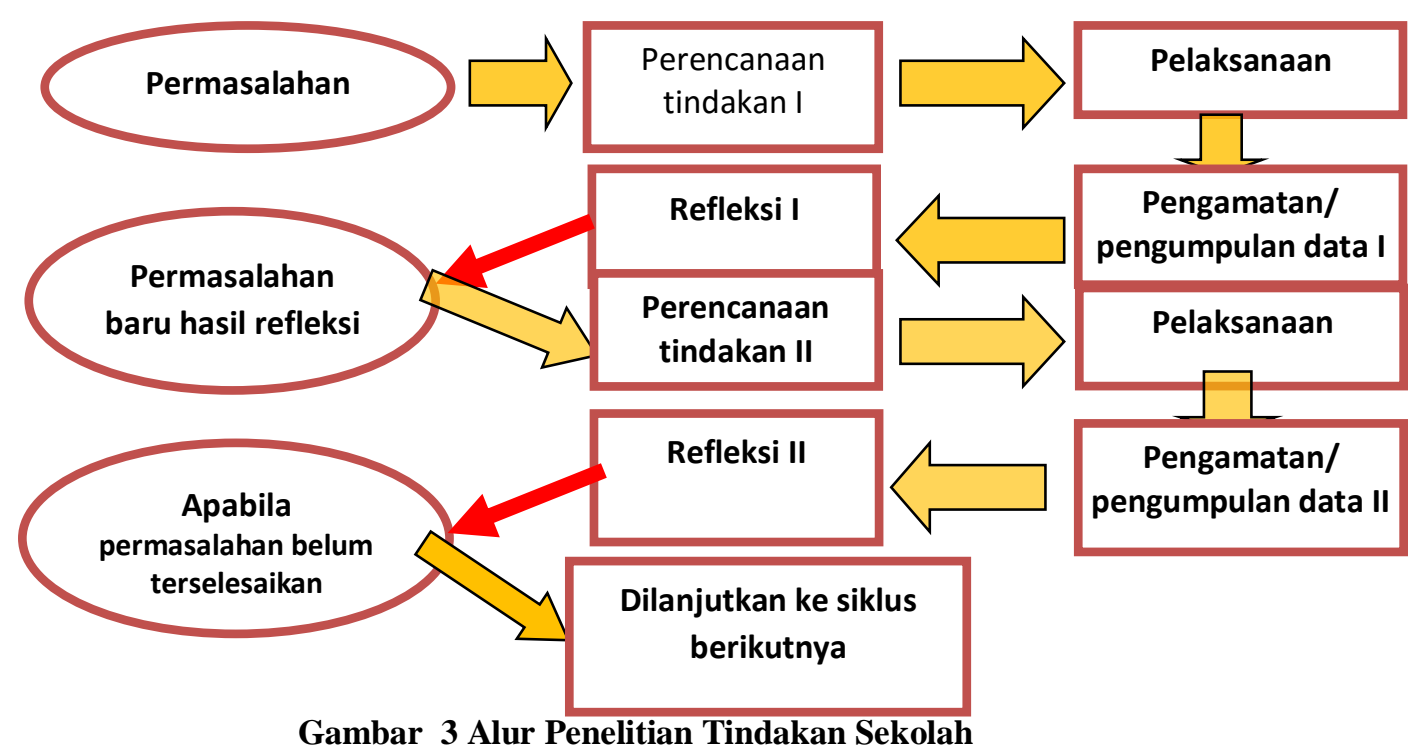

Keterangan : 1) Plan (perencanaan tindakan).

2) Action (pelaksanaan tindakan).

3) Observe (observasi dan interpretasi )

4) Reflect (analisis dan refleksi).

Berdasarkan pretes yang diberi- kan kepada guru kelas I dan kls IV SD sasaran implementasi Kurikulum 2013 diperoleh gambaran tentang kemampuan guru dalam pengelolaan penilaian sebagai berikut:

Tabal 4.1 Test Awal (Pre-test)

\begin{tabular}{clcc} 
No. & Nama & Evaluasi Awal & Kriteria \\
\hline 1 & Elys Widaryati & 60 & Cukup \\
\hline 2 & Ni'mah Pujiastui, S.Pd & 55 & Cukup \\
\hline 3 & Sumiji, S.Pd & 30 & Kurang \\
\hline
\end{tabular}




\begin{tabular}{clcc} 
No. & \multicolumn{1}{c}{ Nama } & Evaluasi Awal & Kriteria \\
\hline 4 & Karsimin, S.Pd & 64 & Baik \\
5 & Ely Pratiwi, S.Pd. & 48 & Cukup \\
6 & Eendang Sayekti, S.Pd & 60 & Cukup \\
7 & Sri Sumarmi,S..Pd,SD & 60 & Cukup \\
8, & Mastuti, S.Pd.SD & 30 & Kurang \\
9 & Nur Azizah,S.Pd,SD & 55 & Cukup \\
10 & Rubi'atun & 30 & Kurang
\end{tabular}

Tabel 4.2. Prosentase Kondisi Awal PengelolaanPenilaian

\begin{tabular}{cccc}
\hline Rentang N & Jumlah Guru & Prosentase & Kreteria \\
\hline $91 \mathrm{~s} / \mathrm{d} 120$ & 0 & $0 \%$ & Sangat baik \\
\hline $61 \mathrm{~s} / \mathrm{d} 90$ & 1 & $10 \%$ & Baik \\
\hline $31 \mathrm{~s} / \mathrm{d} 60$ & 6 & $60 \%$ & Cukup \\
\hline $1 \mathrm{~s} / \mathrm{d} 30$ & 3 & $30 \%$ & Kurang \\
\hline
\end{tabular}

Tabel di atas menunjukkan jumlah/frekuensi kemampuan pengelo- laan penilaian pada kategori sangat baik sebanyak 0 guru $(0 \%)$, kategori baik 1 guru $(10 \%)$, kategori cukup 7 guru $(70 \%)$, dan kategori kurang 3 guru (30\%) Data ini memperkuat asumsi dasar bahwasanya kemampuan guru dalam pengelolaan penilaian, masih perlu untuk ditingkatkan melalui model pendampingan.

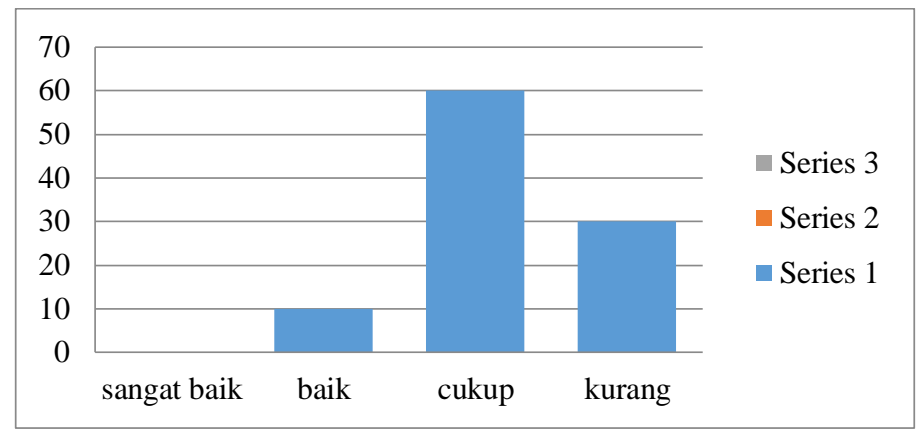

Grafik 4.1. Pretes

Pada dasarnya para guru sudah melakukan pengelolaan penilaian, dan pengawas juga sudah melakukan pendampingan tentang pengelolaan penilaian.Namunpelaksanaan pendam pinngannya secara tuntas dalam pengelolaan penilaian belum maksimal. Di bawah ini disajikan hasil postes siklus 1 pertemuan pertama.

Tabel 4.4. Hasil Postes Siklus 1/Pertemuan Pertama

\begin{tabular}{clcc}
\hline No. & Nama & Pos tes & Kriteria \\
\hline 1 & Karsimin,S.kar & 65 & Baik \\
\hline 2 & Ni'mah Pujiastui, S.Pd & 55 & Cukup \\
\hline 3 & Sumiji, S.Pd & 35 & Cukup \\
\hline
\end{tabular}




\begin{tabular}{|c|c|c|c|}
\hline No. & Nama & Pos tes & Kriteria \\
\hline 4 & Elis Widaryati & 65 & Baik \\
\hline 5 & Ely Pratiwi, S.Pd. & 50 & Cukup \\
\hline 6 & Eendang Sayekti, S.Pd & 65 & Baik \\
\hline 7 & Sri Sumarmi,S..Pd,SD & 65 & Baik \\
\hline 8 & Mtastuti, S.Pd.SD & 35 & Cukup \\
\hline 9 & Nur Azizah, S.Pd & 45 & Cukup \\
\hline 10 & Rubi'atun, S.Pd,SD & 30 & Kurang \\
\hline
\end{tabular}

Tabel 4.5 Kriteria Penilaian Postes dengan 10 item Soal Siklus 1/1

\begin{tabular}{|c|c|c|c|}
\hline Rentang N & Jumlah Guru & Prosentase & Kreteria \\
\hline $91 \mathrm{~s} / \mathrm{d} 120$ & 0 & $0 \%$ & Sangat baik \\
\hline $61 \mathrm{~s} / \mathrm{d} 90$ & 4 & $40 \%$ & Baik \\
\hline $31 \mathrm{~s} / \mathrm{d} 60$ & 5 & $50 \%$ & Cukup \\
\hline $1 \mathrm{~s} / \mathrm{d} 30$ & 1 & $10 \%$ & Kurang \\
\hline
\end{tabular}

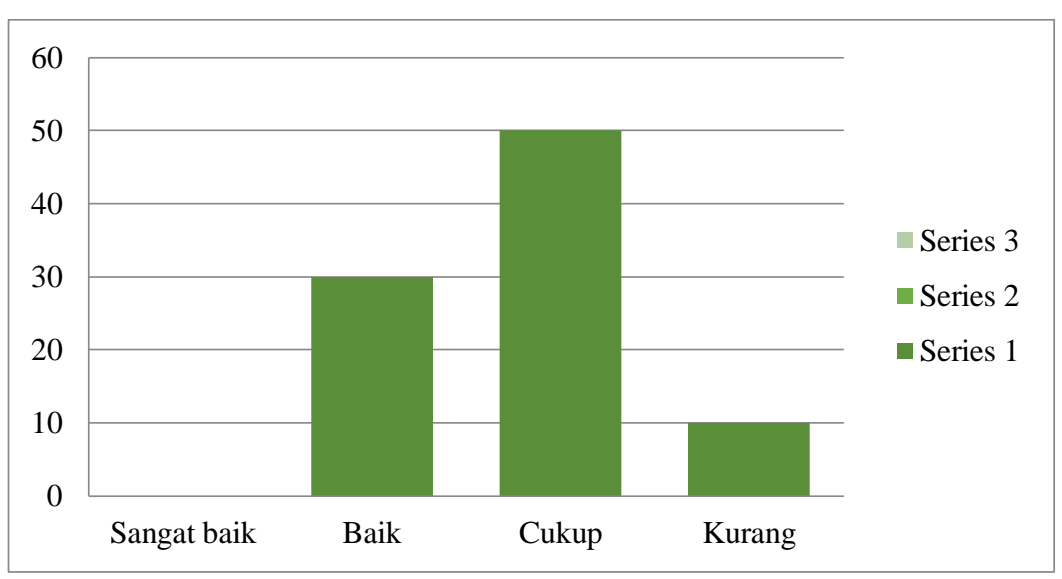

Grafik 4.2 Hasil Pos tes Siklus1 Pertemuan pertama

Tabel 4.6 Postes Siklus 1 Pertemuan ke dua Sebagai Peningkatan dari Siklus I/ ke dua

\begin{tabular}{clcc}
\hline No. & \multicolumn{1}{c}{ Nama } & Nilai & Kriteria \\
\hline 1 & Karsimin,S.kar & 70 & Baik \\
\hline 2 & Ni'mah Pujiastui, S.Pd & 55 & Cukup \\
\hline 3 & Sumiji, S.Pd & 40 & Cukup \\
\hline 4 & Elis Widaryati & 70 & Baik \\
\hline 5 & Ely Pratiwi, S.Pd. & 50 & Cukup \\
\hline 6 & Eendang Sayekti, S.Pd & 70 & Baik \\
\hline 7 & Sri Sumarmi,S..Pd,SD & 70 & Baik \\
\hline 8 & Mtastuti, S.Pd.SD & 40 & Cukup \\
\hline
\end{tabular}




\begin{tabular}{clcc}
\hline 9 & Nur Azizah, S.Pd & 50 & Cukup \\
\hline 10 & Rubi'atun, S.Pd,SD & 40 & Cukup \\
\hline
\end{tabular}

Tabel 4.7 Prosentase Hasil Tes Siklus 1/2

\begin{tabular}{cccc}
\hline Rentang Nilai & Jumlah Guru & Prosentase & Kreteria \\
\hline $91 \mathrm{~s} / \mathrm{d} 120$ & 0 & $0 \%$ & Sangat baik \\
\hline $61 \mathrm{~s} / \mathrm{d} 90$ & 4 & $40 \%$ & Baik \\
\hline $31 \mathrm{~s} / \mathrm{d} 60$ & 7 & $70 \%$ & Ckup \\
\hline $1 \mathrm{~s} / \mathrm{d} 30$ & 0 & $0 \%$ & Kurang \\
\hline
\end{tabular}

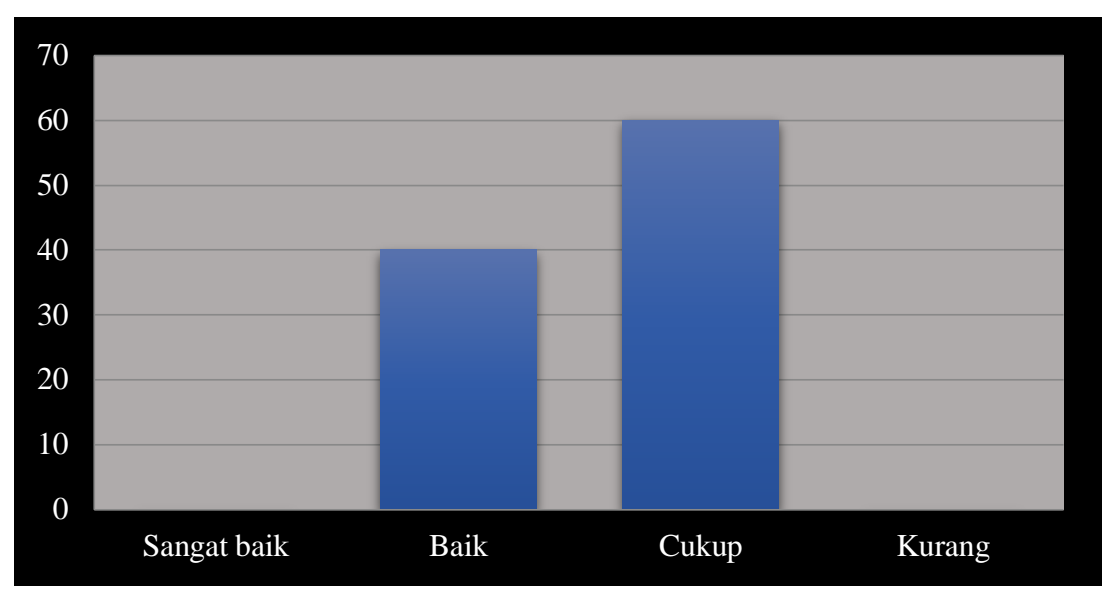

Grafik 4.3 Prosentase Hasil Pos tes Siklus 1/2

Pada siklus 1 pertemuan ke tiga disajikan gambaran perkembangan kemampuan guru dalam pengelolaan penilaian antara pretes dan refleksi siklus 1.Dibawah ini disajikan siklus1. Di bawah ini disajikan tebel perbedaan antara pretes dan refleksi siklus1Tujuan data ini adalah untuk mengecek peningkatan kemapuan guru.

Tabel 4.9 Perbandingan Skor Pre Tes dan Refleksi Siklus I

\begin{tabular}{|c|c|c|c|c|c|c|c|}
\hline No & Nama & Frek \% & Pre Test & Kriteria & Refleksi & Kriteria & Peningkatan \\
\hline \multirow{2}{*}{1} & \multirow{2}{*}{ KS } & $\mathrm{N}$ & 60 & \multirow{2}{*}{$\mathrm{C}$} & 75 & \multirow{2}{*}{ B } & 15 \\
\hline & & $\%$ & 50 & & 62 & & 12 \\
\hline \multirow[b]{2}{*}{2} & \multirow[b]{2}{*}{ NP } & $\mathrm{N}$ & 55 & \multirow[b]{2}{*}{$\mathrm{C}$} & 60 & \multirow[b]{2}{*}{$\mathrm{C}$} & 5 \\
\hline & & $\%$ & 46 & & 50 & & 4 \\
\hline \multirow[b]{2}{*}{3} & \multirow[b]{2}{*}{ SM } & $\mathrm{N}$ & 30 & \multirow[b]{2}{*}{ K } & 45 & \multirow[b]{2}{*}{$\mathrm{C}$} & 15 \\
\hline & & $\%$ & 25 & & 37 & & 12 \\
\hline \multirow{2}{*}{4} & \multirow{2}{*}{ EW } & $\mathrm{N}$ & 64 & \multirow{2}{*}{ B } & 82 & \multirow{2}{*}{ B } & 23 \\
\hline & & $\%$ & 53 & & 68 & & 15 \\
\hline 5 & $\mathrm{EP}$ & $\mathrm{N}$ & 48 & $\mathrm{C}$ & 60 & $\mathrm{C}$ & 12 \\
\hline
\end{tabular}




\begin{tabular}{|c|c|c|c|c|c|c|c|}
\hline & & $\%$ & 40 & & 50 & & 10 \\
\hline \multirow{2}{*}{6} & \multirow{2}{*}{$\mathrm{ES}$} & $\mathrm{N}$ & 60 & \multirow{2}{*}{$\mathrm{C}$} & 76 & \multirow{2}{*}{ B } & 16 \\
\hline & & $\%$ & 50 & & 63 & & 13 \\
\hline \multirow{2}{*}{7} & \multirow{2}{*}{ SS } & $\mathrm{F}$ & 60 & \multirow{2}{*}{$\mathrm{C}$} & 74 & \multirow{2}{*}{ B } & 14 \\
\hline & & $\%$ & 50 & & 62 & & 12 \\
\hline \multirow{2}{*}{8} & \multirow{2}{*}{ MS } & $\mathrm{N}$ & 30 & \multirow{2}{*}{$\mathrm{K}$} & 47 & \multirow{2}{*}{$\mathrm{C}$} & 17 \\
\hline & & $\%$ & 25 & & 39 & & 14 \\
\hline \multirow{2}{*}{9} & \multirow{2}{*}{ NA } & $\mathrm{N}$ & 55 & \multirow{2}{*}{$\mathrm{C}$} & 60 & \multirow{2}{*}{$\mathrm{C}$} & 5 \\
\hline & & $\%$ & 46 & & 50 & & 14 \\
\hline \multirow{2}{*}{10} & \multirow{2}{*}{ RT } & $\mathrm{N}$ & 30 & \multirow{2}{*}{$\mathrm{K}$} & 47 & \multirow{2}{*}{$\mathrm{C}$} & 17 \\
\hline & & $\%$ & 25 & & 39 & & 14 \\
\hline \multicolumn{2}{|c|}{ Rata-rata } & $\mathrm{F}$ & 49,2 & & 62,6 & & 13,4 \\
\hline \multicolumn{2}{|c|}{ Rata-rata } & $\%$ & 40,9 & & 52 & & 11.1 \\
\hline
\end{tabular}

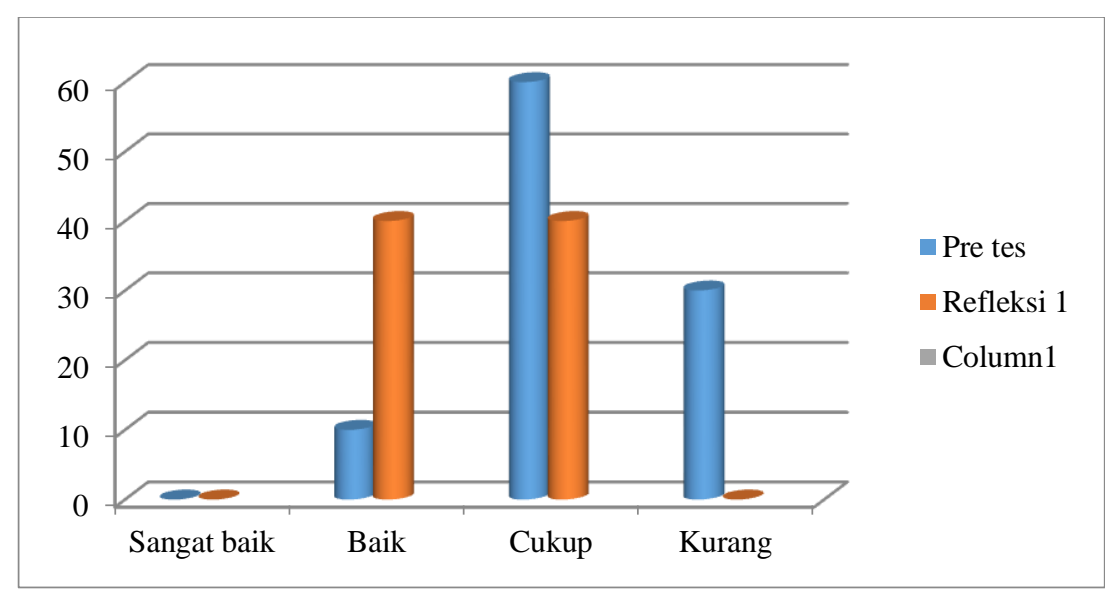

Grafik 4.4 Perbandingan antara Pre tes dan Refleksi 1

Tabel 4.16 Hasil Pre tes, Pos tes dan Refleksi 2

\begin{tabular}{|c|c|c|c|c|c|c|c|c|c|c|c|c|}
\hline \multirow[t]{2}{*}{$\mathrm{NO}$} & \multirow[t]{2}{*}{ Nama } & \multicolumn{3}{|c|}{ Pretes } & \multicolumn{3}{|c|}{ Refleksi 1} & \multicolumn{3}{|c|}{ Refleksi 2} & \multicolumn{2}{|c|}{ Peningkatan } \\
\hline & & Nilai & F\% & Kret & Nilai & F\% & Kret & Nilai & F\% & Kret & $\mathrm{N}$ & $\mathrm{F} \%$ \\
\hline 1 & $\mathrm{KS}$ & 60 & 50 & $\mathrm{C}$ & 75 & 62 & B & 92 & 76 & SB & 32 & 26,66 \\
\hline 2 & NP & 55 & 46 & $\mathrm{C}$ & 60 & 60 & $\mathrm{C}$ & 73 & 68 & B & 18 & 15 \\
\hline 3 & SM & 30 & 25 & $\mathrm{~K}$ & 45 & 37 & $\mathrm{C}$ & 61 & 51 & B & 31 & 25,83 \\
\hline 4 & EW & 64 & 53 & B & 82 & 68 & B & 95 & 79 & SB & 31 & 25,83 \\
\hline 5 & EP & 48 & 40 & $\mathrm{C}$ & 60 & 50 & $\mathrm{C}$ & 74 & 62 & B & 26 & 21,66 \\
\hline 6 & ES & 60 & 50 & $\mathrm{C}$ & 76 & 63 & B & 91 & 75 & SB & 31 & 26,83 \\
\hline
\end{tabular}




\begin{tabular}{ccccccccccccc}
\hline 7 & SS & 60 & 50 & $\mathrm{C}$ & 74 & 62 & $\mathrm{~B}$ & 93 & 77 & $\mathrm{SB}$ & 33 & 27,5 \\
\hline 8 & $\mathrm{MS}$ & 30 & 25 & $\mathrm{~K}$ & 47 & 39 & $\mathrm{C}$ & 62 & 52 & $\mathrm{~B}$ & 31 & 26,66 \\
\hline 9 & $\mathrm{NA}$ & 55 & 45 & $\mathrm{C}$ & 60 & 50 & $\mathrm{C}$ & 78 & 65 & $\mathrm{~B}$ & 23 & 19,16 \\
\hline 10 & $\mathrm{RT}$ & 30 & 25 & $\mathrm{~K}$ & 47 & 39 & $\mathrm{C}$ & 60 & 50 & $\mathrm{C}$ & 30 & 25 \\
\hline \multicolumn{2}{l}{ RATA-RATA } & 49,2 & 40,9 & & 62,6 & 52 & & 77,9 & 65,5 & & 28,7 & 23,91 \\
\hline
\end{tabular}

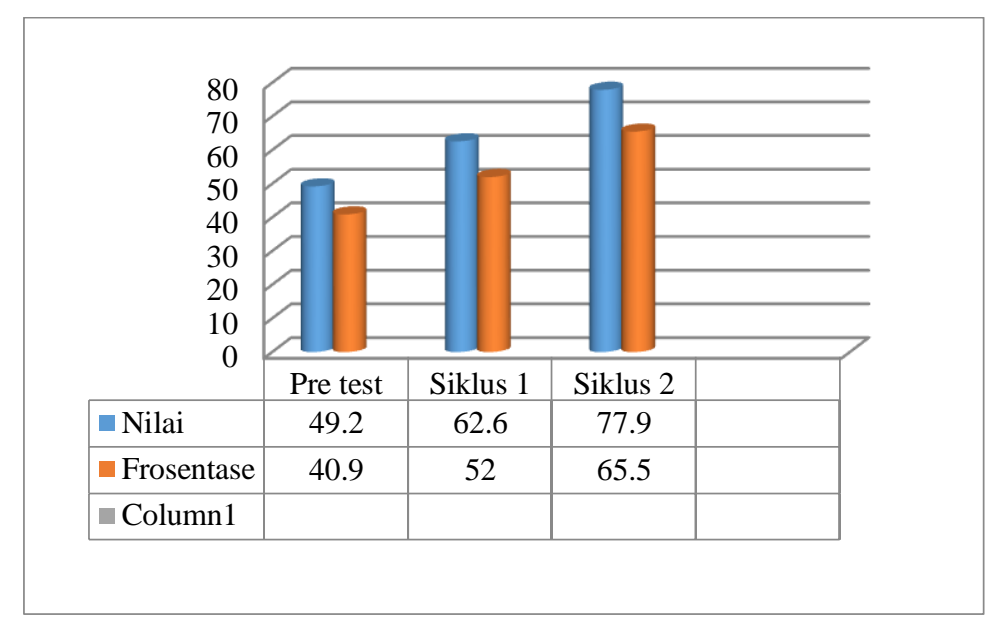

Grafik 4.7 Perbandingan Antara Pre tes, Refleksi 1 dan Refleksi 2

\section{PEMBAHASAN}

Berdasarkan grafik di atas terlihat bahwasanya kemampuan guru yang menjadi subjek penelitian mengalami peningkatan (nilai refleksi lebih tinggi dari nilai pretes, refleksi 1 dan 2 ). Ketercapaian hasil tersebut diperoleh karena berkat pendampingan yang dilakukan oleh peneliti sampai tuntas.

Berdasarkan analisis hasil pendamping an pada bab IV, yang dilakukan peneliti terbukti bahwa model pendampingan tersebut, dapat meningkatkan kemampuan guru dalam pengelolaan penilaian Kurikulum 2013. Hal ini dibuktikan dengan perbandingan peningkatan skor sebesar 28,7 poin atau sama dengan $23,91 \%$

Tabel 4.17 Perbandingan Peningkatan Antara

\begin{tabular}{|c|c|c|c|}
\hline $\mathrm{NO}$ & Kegiatan & Poin & Prosentase \\
\hline 1 & Pre test & 49,2 & 40,9 \\
\hline 2 & Siklus 1 & 62,6 & 52 \\
\hline 3 & Siklus II & 77,9 & 65,5 \\
\hline & $\begin{array}{l}\text { Peningkatan } \\
\text { Pre \& Sik } 2\end{array}$ & 28,7 & 23,91 \\
\hline
\end{tabular}

Pretes, Pos tes Siklus 1, dan Siklus 2.

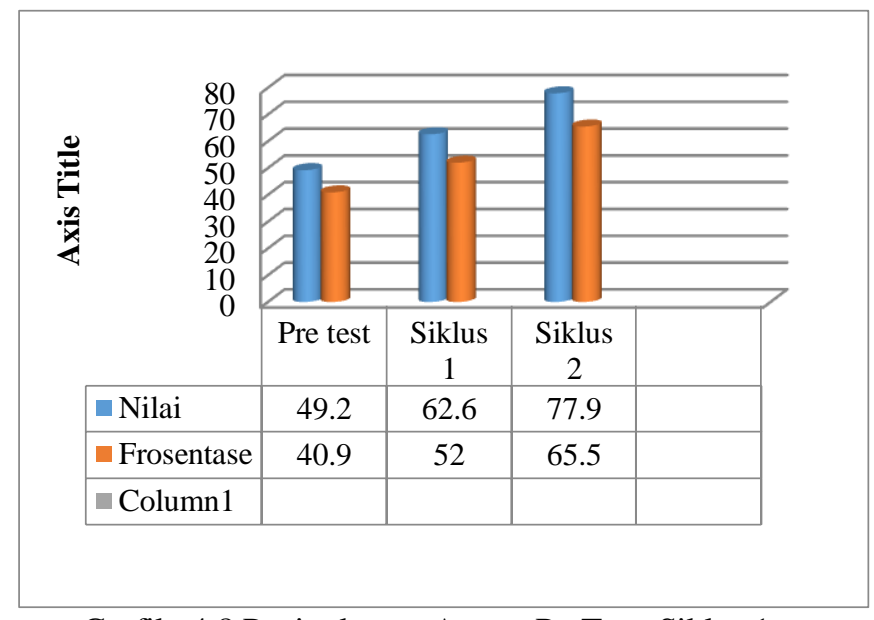

Grafik 4.8 Peningkatan Antara PreTest, Siklus 1,

dan Siklus 2 


\section{SIMPULAN}

\section{Simpulan}

Berdasarkan hasil analisis data dan observasi yang dilakukan oleh peneliti mulai dari tahap awal sampai pada siklus 2 dapat dirumuskan beberapa simpulan sebagai berikut:

Penggunaan model pendampingan bagi guru SD sasaran implementasi Kurikulum 2013 untuk meningkatkan kemampuan guru dalam pengelolaan penilaian, di UPT Pendidikan Kecamatan Jekulo, terbukti berhasil dan efektif, keberhasilan tersebut diketahui melalui hasil analisis peningkatan skor 28,7 poin atau naik $23,91 \%$. Hal ini menunjukkan bahwa tujuan penggunaan model pendampingan yang dilaksanakan peneliti mulai siklus 1 dan 2 dapat tercapai.

Simpulan ini didasarkan adanya peningkatan antara skor evaluasi awal dan refleksi 2, dimana ada peningkatan skor kemampuan guru sebelum dan sesudah diberi bimbingan melalui model pendampingan (ratarata) naik sebesar 28,7 poin atau sama dengan $23,91 \%$. Hasil analisis data tersebut menunjukkan Ho ditolak dan $\mathrm{Ha}$ diterima artinya ada perbedaan antara sebelum diberikan pendampingan dan sesudah diberikan pendampingan.

\section{Saran}

Sekolah diharapkan dapat memperluas jaringan internet dan menambah komputer /laptope bagi guru untuk pengelolaan penilaian dan memberikan kesempatan, dukungan, dan atau fasilitas kepada guru.

Guru diharapkan tidak menge- sampingkan masalah pengelolaan penilaian, tetapi sebaliknya guru harus serius mengembangkannya, karena keberhasilan implementasi Kurikulum 2013 sangat dipengaruhi oleh kemampuan guru dalam pengelolaan penilaian. Guru perlu menjalin kerjasama yang baik dengan sesama guru dan orangtua agar mendapat dukungan dalam kegiatan pembelajaran.

\section{DAFTAR PUSTAKA}

Kementerian Pendidikan dan Kebudayaan Direktorat Jendral Pendidikan Dasar dan Menengah Direktorat Pembi- naan Sekolah Dasar Tahun 2016: Panduan Teknis Pembelajaran dan Penilaian di Sekolah Dasar.

Kementerian Pendidikan dan Kebudayaan Direktorat Jendral Pendidikan Dasar dan
Menengah Direktorat Pembinaan Sekolah Dasar Tahun 2016: Panduan Pelatihan Pendampingan dan Bantuan Pemerintah untuk Pendampingan Kurikulum 2013.

Kemendikbud, 2015 Direktorat Pembinaan Sekolah Dasar Tahun 2015. Manajemen Implementasi Kurikulum

Kementerian Pendidikan dan Kebudayaan Direktorat Jendral Pendidikan Dasar dan Menengah Direktorat Pembinaan Sekolah Dasar Tahun 2015. Evaluasi Diri Sekolah.

Kementerian Pendidikan dan Kebudayaan Direktorat Jendral Pendidikan Dasar dan Menengah Direktorat Pembinaan Sekolah Dasar Tahun 2015. Panduan Penilaian Sekolah dasar.

Kemmis, S. and McTaggart, R.1988. The Action Researh Reader. Victoria, Deakin University Press.

Peraturan Menteri no 23 Tahun 2016, Tentang Standar Penilaian.

Peraturan Menteri no 53 Tahun 2015, Tentang Penilaian Hasil Belajar oleh Pendidik dan Satuan Pendidikan Pada pendidikan dasar dan Pendidikan Menengah.

Suhardjono, Azis Hoesein, dkk. 1996. Pedoman Penyusunan Karya Tulis Ilmiah di Bidang Pendidikan dan Angka Kredit Pengembangan Profesi Widya-iswara. Jakarta: Depdikbud, Dikdasmen.

Suhardjono. 2005. Penelitian Tindakan Kelas. Makalah pada "Diklat Pengembangan Profesi bagi Jabatan Fungsional Guru", Direktorat Tenaga Kependidikan Dasar dan Menengah, Direktorat Jenderal Pendidikan Dasar dan Menengah, Depdiknas 